Conceptual Metaphor In Online News: A Case Study Of Iraq's

Political Situation

by

Saad Saleem Shakir

Prof. Mohammed S. Negm

Professor of Linguistics، Faculty of Arts -Tanta University

Dr. Amal Hamza

Lecturer in English Literature، Faculty of Arts - Tanta University

\begin{abstract}
:
The function of Metaphor has been developed from being an aesthetic tool that depends on comparisons and hyperboles into a mechanism that conveys the author's ideas and beliefs. As life moves towards more practical and materialistic approaches, the aesthetic role of a metaphor becomes more practical. In this regard, the present study aims at highlighting and the use of cognitive metaphor in the Iraqi political context in media. The study highlights and analyzes the main aspects and elements of cognitive metaphors in Iraqi political discourse in media. In this regard, the study adopts an analytical approach for defining and analyzing the aspects of cognitive metaphors adopted in the Iraqi political discourse in different media sources. In addition, the study presents a quantitative part that introduces a statical study of the use of cognitive metaphor in the Iraqi political discourse in media.
\end{abstract}

Keywords: metaphor, types conceptual metaphor, cognitive, political discourse, media in Iraq 


\section{Part One: Introduction}

\section{The problem of the Study}

Generally speaking, the concept of "metaphor" is a pervasive mode of understanding by which we project from one domain of experience to structure another domain of a different kind. So conceived, metaphor is not merely a linguistic mode of expression; rather it is one of the chief cognitive structures by which we can have the coherent, ordered experience that we can reason about and make sense of. (Johnson 1987:xiii-xiv).

\section{Aims of study}

This study aims at identifying and defining the importance of metaphor in English, especially in online news. Showing the most recurring type of conceptual metaphor in online news.

\section{The Procedures of the Study}

The procedures followed in this study are:

A brief account is given to the language of some selected articles on the online sites

particularly the online news.

The theoretical background of the conceptual theory and metaphor its classification and types.

Analysis of the data and followed by the findings of the analytical chapter are presented.

A statistical analysis of the collected data will be presented.

findings are drawn to test the validity of the hypothesis of the present work.

\section{Significance of Study}

The value of the current study can be reflected as in the following: 
1. This study will be advantageous for researchers, linguists, and students. The current work is meant to be beneficial to learners, teachers, linguists as well as researchers examining the area of linguistics.

2. The study presents a good guideline for researchers in the field of linguistics in general. It can enrich her/his knowledge of the linguistic view about the conceptual metaphor in some selected political articles of online news.

\section{Definitions of the Basic Terms:}

\section{1- Metaphor: Basic Concepts:}

There are so many definitions of metaphor in English linguistics; this notion is complex, it can vary from a school of language to another and from a language to another. Lakoff and Johnson (2003:3-4) state that metaphor is pervasive in everyday life, not just in language but in thought and action (i.e. It is a property of concepts and not words). The idea investigated by cognitive linguistics referring to metaphor is the meaning that the humans recognize in a language is primarily based on semantics concepts.

Lakoff (1993) also emphasizes the conceptual nature of metaphor and its hierarchical structure. He argues that metaphor as

a phenomenon involves both conceptual mappings and individual linguistic expression. It is important to keep them distinct since it is the mappings that are primary and that state the generalizations that are our principal concern. For Lakoff metaphor can be understood as a mapping (in the mathematical sense) from a source domain (love) to a target domain (journey). The mapping is tightly structured. There are ontological correspondences according to which entities in the domain of love ( e.g. the lovers, their common goals, their difficulties, the love relationship, etc.) correspond systematically to entities in the domain of a journey (the travelers, the vehicle, destinations, etc.) (ibid: 4).

Mappings are at the superordinate rather than the basic level. For example, in LOVE IS A JOURNEY mapping, a love relationship 
corresponds to a vehicle. A vehicle is a superordinate category that includes such basic level categories as car, train, boat, and plane. It is worth noting that the examples of vehicles are typically drawn from this range of basic-level categories: car (long bumpy road, spinning our wheels), train (off the track), boat (on the rocks, foundering), plane (just taking off, bailing out), It is the superordinate category VEHICLE, not the basic level category CAR that is the general mapping. Thus, the generalization is at the super-ordinate level, while the special cases are at the basic level (Lakoff, 1993:8; Lakoff,1993:6).

\section{2- Types of Conceptual Metaphor:}

Conceptual metaphor theory can be classified according to the cognitive functions that metaphors perform. On this basis, three general types of conceptual metaphors have been distinguished: structural metaphors, ontological metaphors, and orientational metaphors.

\section{A. Structural Metaphor:}

Lakoff and Johnson (2003:14) refer to structural metaphor as "cases where one concept is metaphorically structured in terms of another". In this kind of metaphor; Kovecses (2002:3) claims that the source domain provides a relatively rich knowledge structure for the target concept. In other words, the cognitive function of this type is to enable speakers to understand the target $(A)$ domain using the structure source( B) domain. Knowles and Moon (2006:17) illustrate that the source domains in this type of metaphor supply framework for target domains and this will determine how we think and talk about abstract entities and activities to which the target domain refers. This process is understanding as conceptual mappings between elements of $(A)$ and elements of (B). For example, the concept of Time is structured according to Motion.

-TIMES ARE MOTION. 
One can understand the term "time" as the following element, physical objects, their locations, and their motion. Hence the following mapping will take place as follows:

-You are wasting my time.

-Times are things.

-The passing of time is motion.

-This gadget will save you hours.

\section{B. Ontological Metaphor:}

Ontological metaphors provide much less cognitive structuring for the target concepts than structural ones do. Lakoff and

Johnson(2003:25-26) states that ' ontological metaphors arise when our experience of physical objects and substance provides a further basis knowledge for understanding concrete ones'. Understanding our experiences in terms of objects and substances allows us to pick out parts of our experience and treat them as discrete entities or substances entities or substances of a uniform type. The cognitive job of this type is seeming to give an ontological status to general categories of abstract target concepts ( i.e. we conceive our experiences in terms of objects, substances, and containers in general without specifying exactly what kind of object, Substances and container are meant).

Thus, ontological metaphors explain abstract notions such as time, ideas, inflation, and emotion in terms of objects and substances. The conceptual metaphor such as:

\section{-INFLATION IS AN ENTITY.}

-Inflation is lowering our standard of living.

- If there is much more inflation, we will never survive.

-We need to combat inflation.

- Inflation is hacking us into a corner. 
- Our biggest enemy right now is inflation.

- EMOTIONAL STATES ARE CONTAINERS.

- She is in love.

-We are out of trouble can be now.

- He is coming out of a coma.

- He fell into a depression.

Li (2010:207) Personification can be considered as a form of ontological metaphor. In

personification, human qualities are given to non-human entities personification is very common in literature, but it also abounds in everyday communication such as:

-Life has cheated me.

- His theory explains to me the behavior of chickens raised in factories.

Theory and life are given qualities of human beings such as explaining and cheating( Lakoff and Johnson,2003:33).

\section{Orientational Metaphors:}

They are the metaphorical use of a word with their semantic concepts 'directionality' and 'specialization' where this type organizes metaphors of the many concepts, the one with the other, in the form of the concepts that indicate the place, as in the following examples: -

\section{- Don't force your meanings into the wrong words.}

\section{- Can you extract coherent ideas from that prose?}

The words that are used indicate directionality and specialization which are borrowed here in the abstract expressions of the lingual that have nothing to do with the place at all. These words are all included within the conceptual framework: 
- Linguistic expressions are containers.

Part Two: Theoretical Framework:

Zoltan Kovecses (2010) defines "conceptual metaphor" as understanding one conceptual domain in terms of another conceptual domain in the context of cognitive linguistic view (p. 4). According to this definition, a conceptual metaphor is a kind of thinking or conceptualization. It is basically about two entities or domains: Source domain and Target domain. Source domain is a concept domain used through metaphorical expression to understand another conceptual domain (Target domain).

\section{The Concept of Cognition:}

Cognitive linguistics is an interdisciplinary branch of linguistics, combining knowledge and research from cognitive psychology, neuropsychology, and linguistics. Models and theoretical accounts of cognitive linguistics are considered psychologically real, and research in cognitive linguistics aims to help understand cognition in general and is seen as a road into the human mind. There has been scientific and terminological controversy around the label 'cognitive linguistics'; there is no consensus on what specifically is meant by the term. The term 'cognition is widely used by philosophers and linguists who have drawn skeletons on this field of study. It deals with the connection between concepts and the rules of their use that have not yet been broadly discovered. (Robinson, 2008:8).

\section{Cognitive Linguistics:}

Cognitive linguistics (henceforth, $C L$ ) is a modern school of linguistics and thought that emerged in the late 1960 and early 1970 s in the appearance of cognitive science, especially in the works related to human 'categorization', early work of traditional researches Gestalt psychology'. CL is concerned with investigating the relationship between language, mind, and sociophysical experience (Evans,2007:vi). 
$\mathrm{CL}$ is an approach to the study of language which is based upon human perception and conceptualization of the world. During the twentieth century, the most influential approach to the study of language has been structuralism: linguists have largely devoted themselves to the purely structural aspects of language systems themselves, such as sound systems and grammatical systems.

There are two major tendencies of cognitive linguistics that draw upon semantics, the first one identifies the structure inside the cognitive construction; while the other replaces the idea of twostep models (Keller, 1998: 69).

The theories of cognitive linguistics generally, hold entities of perception, thoughts, feelings, beliefs, intentions; one of these theories suggested by Fauconnier (1985) involves:

\section{Mental spaces.}

2. Cognitive models that structure those spaces.

A mental space is a medium for conceptualization and thought. Spaces are conceptualized in nature. They are not a kind of thing based on the relationship between symbols and things in the real world, but there are dynamic integration processes that build up new blended mental spaces (i.e., conceptual blending) (Lakoff, 1987: 281).

\section{Sub-Approaches of Cognitive Linguistics:}

$\mathrm{CL}$, in general, represents an approach to study the relationship between language, mind, cognition and the external world. CL helps us understand what cognitive processes mean. It is an approach of the language which is divided into sub-approaches cognitive grammar and cognitive semantics. These two subapproaches can be represented in the following figure: 


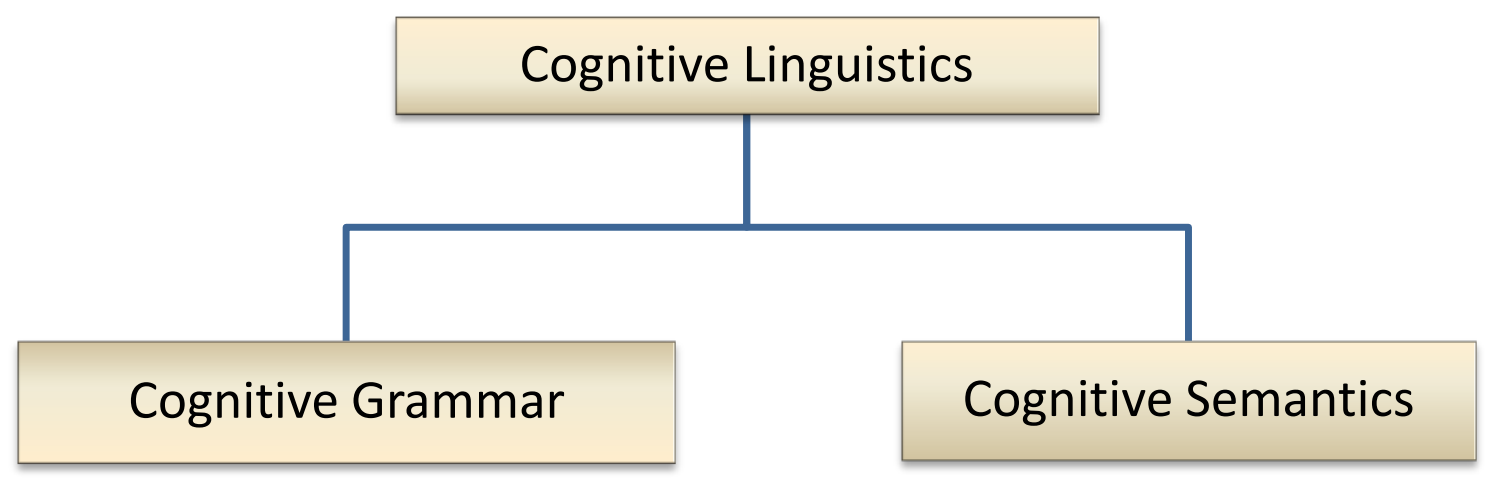

Figure: (1) Sub-approaches of Cognitive Linguistic ( Adopted from Evans and Green, 2006:50).

\section{Cognitive Grammar:}

The first one who suggests a theory called cognitive grammar (hence forth CG) is Ronald. W. Langaker in $(1987,1991)$. CG has a highest effect on cognitive theory. The theory of cognitive grammar considers grammar as a symbolic system like semantics, morphology and syntax. There are no differences between grammar and semantics because both of grammatical categorization and meaning construction related to a symbolic system. CG differs from traditional and structural grammar because it considers grammar as conceptual structures. Many cognitive linguists give attention to the linguistic sign that is found in semantics, morphology, and analysze them in mapping correspondence, but only Langaker sheds the light on grammar by considering it to be like other conceptual systems (Saeed,2003:374).

Evans and Green (2006:501) define CG as our linguistic knowledge 'the mental grammar' which exists in the speaker's mind "as lists of symbolic units, these symbolic units are not built structurally into language system, but are stored and accessed as a whole". These symbolic units are built on speaker's grammar as conventional phenomenon which has a strong relationship with the linguistic expressions, especially when they are shared be a 
certain group community. When these symbolic units are related to each other, another relation that is known as a network appears.

\section{Cognitive Semantics:}

Cognitive semantics (henceforth, CS) is defined as "a branch of cognitive linguistics which assumes that language is a mental ability which is sub- structured by certain forms of knowledge". Many semanticists see that language must have a relation with cognition in order to have sense and meaning. Thus, knowledge cannot be isolated from cognition because linguistic knowledge is a part of cognition. Meaning in CS is based on conventionalized conceptual structure, thus mental categories which people have shaped from their experience of an external world are reflected by cognitive domain to contain the semantic structure (Saeed,2003:342).

\section{Image schema Theory:}

Image schema has been developed within cognitive semantics to be the most influential area for studying psychological developments and the development of an embodied cognitive thesis. (Evans and Green,2006:177).

Evans and Green (2006:185) give brief but sufficient difference between image schema and mental image, by giving example "close your eyes and imagine your father or mother) the image that appears when you close you are in the mental image because it has a strong relationship with reality result from conscious cognitive experiences and recalling for 'visual memory, while the image schema was more abstract found in our embodied experiences that meant we cannot imagine it. Saad (2003:353354) defines image schema as the central conceptual structure of cognitive semantics. The most important idea of image schema is to structure our experience, acting, and being in the world, exercising our force and moving of our bodies all these functions 
depend on the conceptual structure which organizes our thought through a more abstract domain. He gives certain examples of image schema as follows:

1- Containment schema which drives from our everyday experience, considering our bodies as the container of our emotions, thought, and ideas. Our experience becomes as physically located within bounded locution like room, bed,..etc. Lakoff and Johnson (2003: ) conceder image schema as an ontological metaphor (non-physical phenomenon describe in a physical one. The example below by Saad will describe this type clearly " I put a lot of energy into washing the window"

Energy (non-physical or abstract term) understand by (physical or visual term) window.

2- Path schema: Saad mentions that this example of image schema is used for experiencing the movements of entities stored in our mind reflecting our daily activities and how these activities moving in the world. Any path must have a starting point and ending point the space between these points known as a path.

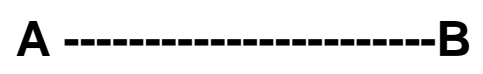

\section{Path}

The relation between $A$ and $B$ are as follows: $A-A$ and $B$ are interacted by series of neighboring location, getting from $A$ to $B$ is moving through intermediate locution. $b$-Path tends to be related with direction movement along with $A$ from $B$. $C-A$ and $B$ are related to each other by time and temporal sequence.

3- Force schema is like other types of image schema that grew inside us since childhood, rising from everyday experience, surrounding our environment, and interacts with animate and animate entities. Shaping from our linguistic categories. All these examples of image schema are considered as pre-linguistics phenomena. 
To sum up, image schema is part of our perceptual system depends on our experience of the physical world, some semanticists consider it as part of the pre-linguistic phenomenon, because it considers as the outcome of our interaction of external world, it gives coherence and helps us to understand different concepts in our minds.

\section{Conceptual Metaphor Theory:}

Johnson (1987:69) points out that despite the dominance of the objectivist orientation in the Western philosophical tradition, there have been notable voices of the opposition who have claimed for metaphor a serious, creative, and constitutive role.

It was until the twentieth century when I. A. Richards (1936) initiated a revival of interest in metaphor by arguing that thought is irreducibly metaphorical and that linguistic metaphors are manifestations of these underlying metaphoric thought processes. In reviving the study of metaphor, I . A. Richards offered a terminology that has become widely accepted in talking about metaphor. According to him, metaphor consists of two terms (topic and vehicle) and the relation between them (ground). The notion of tension is also introduced by Richards to describe the literal incompatibility of the topic and vehicle (Gibbs, 1994:211).

\section{Part Three: Discourse Analysis in The Context of Conceptual Metaphor}

Iraq is a well-established country with a long and fascinating history. The last three decades witnessed many political and military events that changed the political scene in Iraq. The First and Second Gulf War, the American Invasion in 2003, and the fierce political situation have made up a complicated political situation in Iraq. This complicated political situation has a great impact on media. The Iraqi political scene has largely been introduced in the media. This attributes the Iraqi political discourse to many cultural and linguistic features. One of the remarkable linguistic and cultural phenomena that distinguish the political discourse associated with Iraq in media is a metaphor. 
Using cognitive metaphors in the Iraqi political discourse in media raises an important question: Are cognitive metaphors regarded as a linguistic or figurative device when they are used in the political discourse? Modern use of Cognitive metaphors highlights the flexibility of metaphors as a multi-device that can be used as a literary device that introduces ideas in terms of comparisons and hyperboles, besides the linguistic usage of metaphor as a mechanism through which the author / content maker can introduce his ideas and thoughts.

In this regard, this part has two major parts. The first part of this chapter discusses the main elements of the political discourse, especially in media through discussing and analyzing the main elements of both media language and political discourse. In addition, this part clarifies the connections between media language and conceptual metaphor besides discussing media language usage of conceptual metaphor. This part discusses the importance of using cognitive metaphor in the titles and headlines of media as the gate through which the reader/audience receives the content. Furthermore, this part elaborates the modern usage of cognitive metaphor as a linguistic element rather than the rhetorical element.

The second part of this chapter employs a statical approach for defining and analyzing the most used types of conceptual metaphors. Furthermore, it analyzes and investigates the use of cognitive metaphors in each type of media highlighting the impact of using cognitive metaphors within the piece of media itself. Moreover, this part connects the metaphorical expression either negative or positive to the political discourse and its purpose.

Media language is regarded as one of the most elements of media as a product that has a specific function to that communicate meanings to receivers either readers or audiences. These meanings include a wide range of terms including visual codes, audio codes, technical codes, and language. However, still, the element of language is the most important part of media as it represents the verbal element that decodes and illustrates all other 
visual and auditory elements. Here, it is necessary to define the term media first to be able to discuss and analyze media language. Media, generally, represents various methods of communications that convey a certain message to receivers. These methods include many verbal and visual devices such as radio, newspapers, the Internet, and television (Martinec, p.20, 2020)

\section{Political Discourse}

Before discussing the use of cognitive metaphor in the Iraqi political scene in media, it is necessary to define and analyze the main aspects of the political discourse. Two main theoretical concepts can define and analyze the political discourse. The two concepts are set by Paul Chilton (2004) in his book, Analysing Political Discourse: Theory and Practice. The first concept set by Chilton the context which is discussed in terms of "a struggle for power" between two parties: the first party aims to keep their power and enlarge it, whereas the second party stays against the first party to gain "some" or "all" of this power $(2004$, p.3). In the Iraqi political context, this definition can be noticed through the First Gulf War, Second Gulf War, and the American Invasion (2003).

The best words that describe that connection between media, linguistics, and political discourse are Wodak's (2009) as she mentions:

Political discourse includes different genres such as political speeches, press conferences, interviews with politicians, reports on different political events in the press, and since politics includes persuasion, rhetoric, and delusive devices, politicians employ different discursive strategies to achieve their goals. ( qtd. in Stojan, p. 70, 2019).

Thus, Wodak (2009) argues that political discourse is the discourse that communicates a message to the receiver through different political genre Borčić, Kanižaj \& Kršul, 2016 argues that political discourse is interrelated to many various genres. One of these genres is persuasion that is defined as an area of linguist 
studies and politics it plays the most important part in shaping the political discourse features.

In this regard, the elements of persuasion are very important in shaping all political discourse. In other words, language is a very important element in poetic discourse. Persuasion is the main tool through which a politician can convey his point of view in the political discourse. Persuasion can be achieved through language that has three main Aristotelian elements: 1) logos or logic; 2) ethos or ethic; and 3) pathos or emotion (Braet, 1992, p.310).

\section{Cognitive metaphor, media, and politics:}

Cognitive science is the interdisciplinary field that studies the human mind and its processes (Thagard 1996). Cognitive science testifies and analyzes the nature, missions, and tools of cognition. In other words, it is associated with how the human mind conveys messages. Many linguists and cognitive scholars assert the connection between political theory and conceptual metaphor in both political and linguistic areas.

In this context, the scholar of this approach of linguistics aim at highlighting and focusing on the way through which an idiom can make up the Conceptual metaphors; however, actual grammar, besides the basic cross-cultural elements of the scientific approach aimed at minimizing the influence of cognitive metaphors, especially in scientific and political areas. This claim is made due to the aesthetic and imaginative impact of metaphors in any text.

Lakoff rejects the concept of " Natural language semantics that is defined according to mathematical logic" (Davidson \& Harman, 2012, p. 772 ). The concept of "generative grammar|" set developed by Chomsky did not discuss and analyze the concept metaphor logically as a part of the science of semantics as it is discussed and analyzed as a part of grammar (Kratzer \& Heim 1998). Thus, Lakoff asserts that this grammatical element makes "artifice out of natural language and is therefore untenable." (Paulson, 2019, p.46). 
Conceptual Metaphors in the Titles and Headlines of media in Iraqi's Political Scene:

The title is the gate through which the media is presented to the receiver. Modern and recent theories highlight the role of the title in introducing the discourse to the reader/audience. That is why the title is responsible for making up the reader/author or sender/receiver relationship. The French theorist, Gérard Genette argues that the title is one of two pillars of the text (the paratext). (1991, p.262). In terms, of cognitive metaphor, the titles of the samples either texts, videos, or online websites showed heavy use of cognitive metaphor. This use reflects the importance of cognitive metaphor as a linguistic and intellectual tool in shaping the title as the gate of the text. That is to say, most examples clarify that titles and headlines have the largest share of using cognitive metaphors. The importance of titles and headlines in the political discourse and media language can be described as Chen argues:

A headline is the refining of a news report. An audience of traditional media often firstly look at the news headline to make sure whether they would like to go on reading the content of the news report. If time is limited, they would select news to read according to the headline of it. In this information technology era, only when a reader is interested in the news headline, will he click the link to read the whole news report? Therefore, to attract readers to read the news report to an extreme, to have an important impact on the spreading efficiency of news, an author will adopt a variety of approaches to make the headline more vivid. Metaphor is one of the most frequently used rhetorical devices to enhance the effect of expression and efficiency of spreading (Chen, 2018 p.327).

Thus, titles and headlines contain more conceptual metaphors than any other part of the piece of media as they either represent the portable that the reader will receive the message through it; or the reader will only read the headline and neglect the other parts of the piece of media. Here, the following examples highlight the importance of using cognitive metaphors in titles and headlines: 
"Where does Iraq fall in the US administration policy?" (Middle East Monitor 2020)

Iraq War - 9 April 2003: The fall of Baghdad (RFI English YouTube channel 2020)

The Fall of Saddam and Rise of ISIS (Foreign Policy Association YouTube Channel, Dec 22, 2015)

Iraq/Kuwait - Saddam Retains Leadership (Jul 21, 2015, APA)

"15 years after Saddam's fall, Iraqi hopes fade" (AFP News Agency, Apr 6, 2018)

"EU moves to remove Iraq from high-risk countries list" (Arab News, Updated 12 January 2021)

Most of these examples which are mentioned in the titles and headlines in much online news (samples) highlight a heavy use of the "ontological" cognitive metaphor. The use of the expression "fall" is used for highlighting the defeat of Iraq or the defeat of Saddam Hussein. The concept of "fall" is an iconic metaphorical expression which mainly associated with the idea of fallen angels derived from the Book of Enoch, a Jewish pseudepigraph (Kaske, 1971, p.426). In addition, in terms of metaphorical aspect, and from an archetypal point of view, the expression of "fall" is pictured as decadence, loss, or dying stage (Cobb 1992) The main object of using ontological conceptual metaphor is to depicting the experience of Iraq or Saddam as a physical object that fall. In other words, these headlines conceptualize the experience of Sadam or Iraq through the means of structural metaphor.

\section{The Use Of Cognitive Metaphor In The Body Of Media In The Iraqi's Political Context:}

The use of cognitive metaphor in media in the Iraqi political scene news is not only related to the titles and headlines, but it penetrates each part of the political news text. For example, the following pieces of news highlight the use of cognitive metaphor in 
media language of texts that are associated with the Iraqi political scene:

The Long Game in Iraq

How to Counter Iranian Influence in Baghdad.... (Robert S. Ford and Randa Slim

September 30, 2019)

The above-mentioned cognitive metaphor is very familiar in the domain of politics. The political conflicts are always depicted as a "game." Both politics and sports share the element of "conflict." Thus, depicting a political situation as a "game" is the common cognitive metaphor that clarifies the author's thoughts using his style and ideas.

\section{Conclusion}

The metaphor was known as a rhetorical device that depends on comparisons; however, the modern use of metaphor has transformed this literary device into a linguistic device that represents thoughts and ideas. Most modern definitions of metaphor agree that metaphor is thoughts, ideas, and actions. Conceptual metaphor is a type of metaphor that touches everyday language. Cognitive metaphor has three main types: 1) structural metaphors; 2) ontological metaphors; 3) and orientational metaphors. All these forms depend on the function through which the target domain is associated with the source domain to convey a certain thought.

Culture and metaphor are related to each other as the metaphor will never be understood without considering the cultural background of the source and target domain.

The study argues that cognition, as the main drive of cognitive metaphor, shapes organizes the approaches that humans think and produce their language. In terms of linguistics and cognition, 
language is considered a mirror of human cognition because cognition is considered the source of the data that connect the human mind to the outer world.

In linguistic studies, cognitive linguistics is divided into two main categories: cognitive grammar and cognitive semantics. Cognitive linguistics asserts that cognitive grammar, cognitive semantics, and lexicon are on a continuum rather than separate processes altogether. Many theories analyze and interpret the concept of metaphor. Image schema theory has been developed within cognitive semantics depends on the psychological approach through investigating the difference between image schema and mental image. Unlike image schema theory, mental space theory argues that "discourse "is the subclass of different mental spaces including what is called "counterparts and connectors". The modern approach of cognitive metaphor asserts the linguistic function of metaphor, unlike the traditional approaches that regard metaphors as a mere literary device.

There are four main traditions of classifications of cognitive metaphors. According to the cognitive function, there are three categories of cognitive metaphors: structural, oncological, and orientational. The second classification is set according to conventionality: dead and alive cognitive metaphor. The third classification depends on the generality of the metaphor. This classification divides cognitive metaphors into general and specific. The last traditional classification divides cognitive metaphor into two main categories: universal and culturally specific.

Generally, the study has asserted the remarkable use of cognitive metaphor in the media language that is associated with the Iraqi political scene. Cognitive metaphors in the Iraqi political scene asserted the modern use of metaphor as a linguistic device for conveying ideas and thoughts. This modern use eliminated the traditional use of metaphor as a rhetorical device utilized in literary discourse.

The study has asserted that titles and headlines use cognitive metaphor as a linguistic device for paving the way for the author/ 
content maker's ideas and thoughts. The use of cognitive metaphor in titles and headlines emphasizes the modern use of metaphor as a method for conveying thoughts and ideas rather than a figurative device. In addition, the study has elaborated that most cognitive metaphors analyzed in the study used politics as a target domain, whereas they used different common domains as a source such as sports, journeys, and roads.

The study has divided cognitive metaphors into a new category that is associated with the idea of the author/content maker. This category divides cognitive metaphors into three types: positive, negative, and neutral. Positive cognitive metaphor conveys positive expressions. A negative metaphor conveys negative ideas and expressions. Neutral metaphors convey the author's ideas without giving positive or negative implications. As the study, discusses and analyzes the Iraqi political discourse that has always been associated with political conflicts, wars, and the American invasion, most cognitive metaphors were negative.

As a final point, the study suggests further studies that are associated with cognitive metaphors as cognitive metaphors in translation may be a very interesting topic in the translation studies arena due to metaphor's connection to cultural aspects, especially in translation. In addition, more studies are needed to discuss and analyze the modern concept of metaphor that deals with metaphor as a linguistic device rather than a literary device.

\section{References}

- AFB, (2018) "15 years after Saddam's fall, Iraqi hopes fade" AFP News Affairs. Agency, Apr 6, 2018.

- AL-Samarrai, M. (2012) "Iraq's Political Game."Al-Monitor. Dec 9, 2012.

- APA (2015). "Iraq/Kuwait - Saddam Retains Leadership" (Jul 21, 2015, APA) 
- Arab News (2021) "EU moves to remove Iraq from high-risk countries as text and talk: Analytic approaches to political discourse 203

- Barcelona (2000). "Introduction: the cognitive theory of metaphor and metonymy". In: Barcelona, A.(ed.), Metaphor and Metonymy at The Crossroads. Berlin and New York: Mouten de. Gruyter, pp. 1-28.

- Borčić, N, Kanižaj, I, Kršul, S. (2016). Conceptual Metaphor in Political communication. Zbornik Sveučilišta u Dubrovniku. 73-94.

- Badley, K., \& Van Brummelen, H. (Eds.). (2012). Metaphors we teach by How metaphors shape what we do in classrooms. Wipf and Stock Publishers

- Chen, B. (2018, September). Metaphors in English News Headlines. In 2018 International Symposium on Humanities and Social Sciences, Management and Education Engineering (HSSMEE 2018). Atlantis Press.

- Chilton, P. A. (2004). Analyzing political discourse: Theory and practice. Psychology Press.

- Evans, Vyvyan; Melanie Green (2006). Cognitive Linguistics: An Introduction. Edinburgh University Press.

- Fliervoet, F. (2017)."The survival Game." Open democracy.11 October 2017.

- Foreign Policy Association YouTube Channel. (2015) "The Fall of Saddam and Rise of ISIS." Dec 22, 2015.

- Kovecses, Z. and G. Radden (1998). "Metonymy: developing a cognitive linguistic view". Cognitive Linguistics, 9-1: pp.3777. 
- ---.(1993a). "The Contemporary Theory of Metaphor". In: Ortony, A. (ed.), Metaphor and Thought ( $2^{\text {nd }}$ edition). Cambridge: Cambridge University Press.

- Lakoff, G , and M. Johnson. (1980). Metaphors We Live By. Chicago: Chicago University Press.

- Lakoff, G, and M.Turner (1989). More Than cool Reason. A field Guide To Poetic Metaphor. Chicago: University of Chicago Press.

- Lakoff, G. and Z. Kovecses (1987). "The Cognitive Model of Anger Inherent In American English”. In: Holland, D. and N. Quinn (eds.), Cultural Models In Language and Thought. Cambridge: Cambridge University Press.

- Mahadi, T. S. T. Jafari, S. M. (2012). Language and Culture Vol. 2 No. 17University Sains Malaysia.

- Middle East Monitor (2020) "Where does Iraq fall in the US admit from conceptual metaphor nitration policy?"

- Martinec, R., \& Van Leeuwen, T. (2020). The language of new media design: Theory and practice. Routledge.

- Nordquist, R. (2019). "Definition and Examples of Ontological Metaphor." Thought. https://www./ontological-metaphorterm-1691453

- Nosek, B. A., Graham, J., \& Hawkins, C. B. (2010). Implicit political cognition.

- --- (ed.)(1993). Metaphor and Thought. (2 ${ }^{\text {nd }}$ edition). Cambridge: Cambridge University Press.

- RFI English YouTube channel. (2020) Iraq War - 9 April 2003: The fall of Baghdad.

- Stojan, N., \& Mijić, S. N. (2019). Conceptual Metaphors in Political Discourse in Croatian, American ,and Italian 
Newspapers. Academic Journal of Interdisciplinary Studies, 8(1), 69.

- VOA. (2010). "Results Released Friday Show Iraqi PM Still In Tight Race." VOA News TV.Mar 15, 2010.

- Walther-Hansen, M. (2020). Making Sense of Recordings: How Cognitive Processing of Recorded Sound Works. Oxford University Press.

- Winters, C. T. (2020). Composing the Conceptual Metaphor Argument is War. In Argument is War: Relevance-Theoretic Comprehension of the Conceptual Metaphor of War in the Apocalypse (pp. 52-160). Brill. 
الاستعارة المفاهيمية في المقالات الاخبارية مع التطبيق على الوضع السياسي في العراق

$$
\text { إعداد/ }
$$

\section{سعد سليم شاكر}

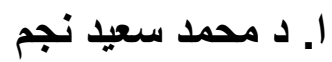

أستاذ اللغويات كلية الآداب- جامعة طنطا

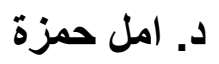

مدرس الأدب الإنجليزي كلية الآداب- جامعة طنطا

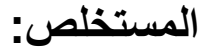

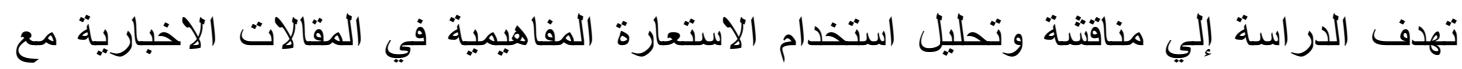
التطبيق على الوضع السياسي في العراق حيث تناولت الدراسة الأنواع المختلفة من الاستعارة

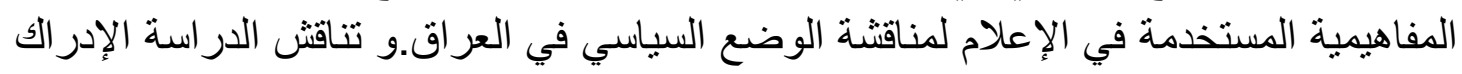

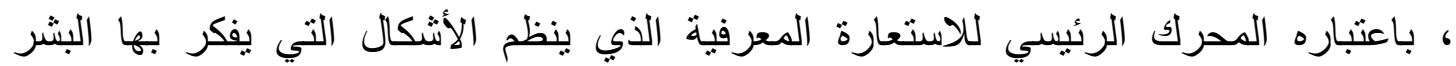

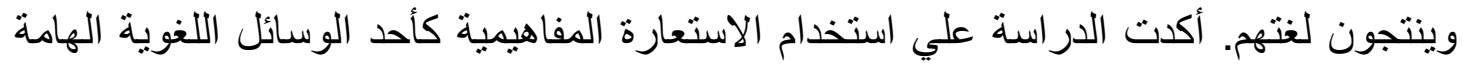

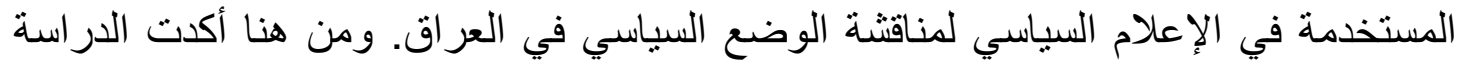

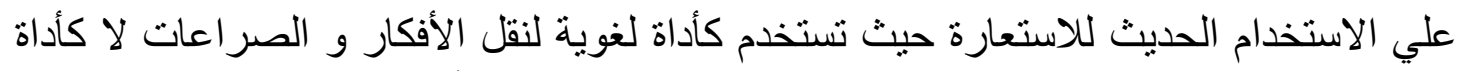

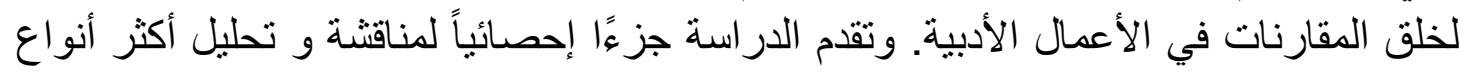

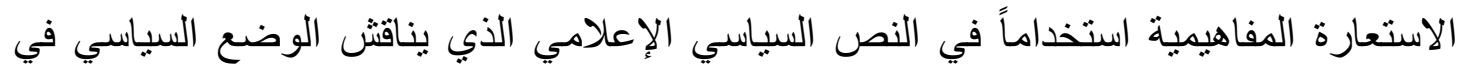

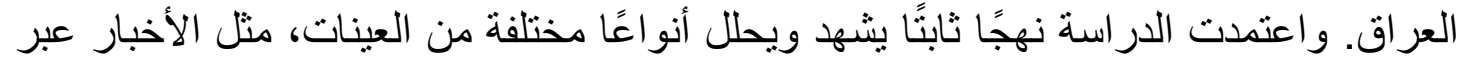

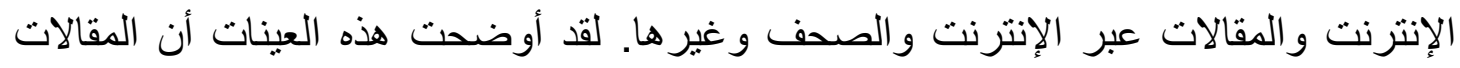

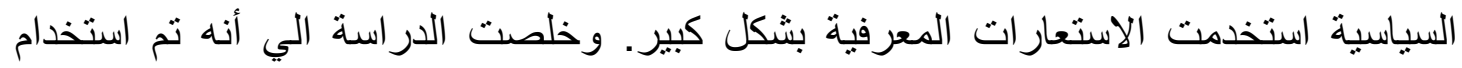

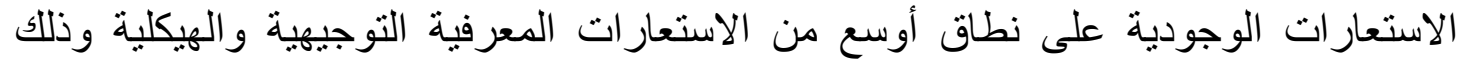
لقوتها وفعاليتها في توصيل الأفكار وكذلك ملائمتها للاستخدام الحديث للاستعارة المفاهيمية

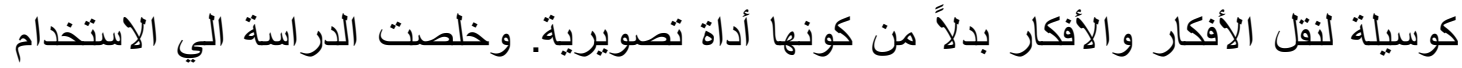

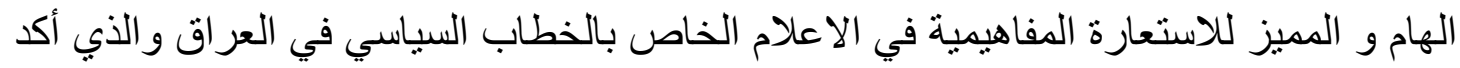
علي الاستخدام الحديث للاستعارة المفاهيمية كوسيلة لنقل الأفكار و امكانية استخدامها في الخطاب السياسي و الإعلامي.

الكلمات الإفتتاحية: استعارة ، أنواع استعارة مفاهيمية ، معرفي ، خطاب سياسي ، إعلام في العراق 